\title{
CLASSES SOCIAIS, TRAJETÓRIAS DE VIDA E LUGARES DE PODER \\ UMA ABORDAGEM ETNOGRÁFICA DA REPRESENTAÇÃO POLÍTICA
}

\author{
SOCIAL CLASSES, LIFE COURSE AND POWER \\ AN ETHNOGRAPHIC APPROACH OF THE POLITICAL \\ REPRESENTATION
}

\author{
João Mineiro \\ Instituto Universitário de Lisboa (ISCTE-IUL) \& Centro em Rede de Investigação em Antropologia (CRIA). \\ Av. das Forças Armadas, Edifício ISCTE-IUL, 1649-026, Lisboa, Portugal. Email: joao.mineiro.6@gmail.com
}

\begin{abstract}
Resumo: A Assembleia da República é um dos mais importantes órgãos de soberania do Estado português. Mas o que é que a caracteriza sociologicamente? Tendo por base uma etnografia do Parlamento, propõe-se três argumentos. O primeiro é o de que a representação política é socialmente circunscrita: tendencialmente dominada por homens, brancos, qualificados, com formações dominantes em direito, economia e gestão, oriundos do litoral e que se inserem em lógicas de polienvolvimento político. Depois, defende-se que a ação individual dos eleitos só pode ser compreendida a partir da sua inserção num mundo hierarquizado, que agencia determinadas pessoas em detrimento de outras. Finalmente, conclui-se que distintas pertenças de classe potenciam ou inibem o acesso, adaptação e permanência ao campo político. Campo, esse, onde a desigual distribuição do capital político, uma forma de capital compósito, simultaneamente cultural, social e simbólico, estabelece um conjunto de fronteiras entre quem está dentro e quem está fora, entre quem pode representar e quem deve ser representado.
\end{abstract}

Palavras-chave: Parlamento, representação política, classes sociais, democracia.

\begin{abstract}
Assembleia da República is one of the most important sovereignty body of the Portuguese State. But what characterizes it sociologically? Based on an ethnography of the Parliament, this study proposes three arguments. The first is that political representation is socially confined: tendentially dominated by white men, qualified, with dominant formations in law, economics and management, coming from the largest urban areas and participating in a multiple political environment. Next, it is argued that individual action of the members of parliament can only be understood from its insertion in a highly hierarchical world. Finally, it is proposed that distinct class positions enhance or inhibit access and adaptation to the political field. This is a field where the unequal distribution of political capital, a form of composite capital, simultaneously cultural, social and symbolic, establishes a set of boundaries between who is inside and who is outside, between who can represent and who should be represented.
\end{abstract}

Keywords: Parliament, political representation, social classes, democracy.

\section{Entrar na Assembleia: Introdução e pontos de partida}

A Assembleia da República é uma das mais importantes instituições políticas do Estado português, sendo o único órgão de soberania política e ideologicamente 
plural, onde semanalmente 230 deputados, eleitos por sufrágio universal, têm como missão formar uma "assembleia representativa de todos os cidadãos portugueses"1. Assembleia, essa, que deve representar politicamente os cidadãos, produzir grande parte da legislação do país, escolher o Governo, e ao mesmo tempo escrutinar a sua atividade e a da administração pública.

A importância destas funções faz desta instituição um objeto de estudo frequente, analisado a partir de diversos ângulos disciplinares. Além, claro, de ser alvo de uma forte atenção mediática, bem patente nas dezenas de jornalistas que todos os dias passam o controlo de segurança na porta lateral do Palácio de S. Bento.

Mas o que caracteriza sociologicamente esta "assembleia representativa de todos os cidadãos"? Quem são as pessoas que exercem esse poder particular que designamos por representação política? O que representam os representantes do povo?

Estas foram algumas das perguntas que guiaram a etnografia do Parlamento português que realizei entre outubro de 2015 e julho de 2018. Um método que me levou aos corredores da Assembleia da República, com a finalidade de conhecer como se constrói no quotidiano, aquilo que abstratamente se designa por "democracia parlamentar". Uma abordagem que procurou os detalhes impercetíveis nas leituras normativas, abstratas ou exclusivamente quantitativas da análise do sistema político. Colocou-se, então, o foco nas pessoas concretas, nas suas interações quotidianas, nos seus discursos e nos seus contextos de ação.

Este método de investigação nunca havia sido aplicado a esta instituição e permitiu analisar o funcionamento quotidiano do Parlamento, a partir de uma pesquisa de terreno prolongada e intensiva, através da qual foi possível observar, entrevistar e acompanhar um conjunto de atores sociais que ali interagem. Nas próximas páginas procuro mostrar quem são os deputados portugueses, quais as suas origens sociais e trajetórias biográficas, e de que forma elas se traduzem em distintos modos de agencialidade política. Além disso, desenvolve-se uma análise sobre a forma como a ação individual dos eleitos é pensada e moldada a partir da sua inserção num mundo altamente hierarquizado, onde a posição relativa face a autoridade, abre e fecha campos de representação e ação política, e onde as sociabilidades ganham contornos muito particulares. Finalmente, avança-se com uma proposta de articulação das noções de classe social, trajetória de vida e representação política, na procura das determinantes sociais e culturais que nos permitem pensar a noção de campo político, recurso analítico mais amplo, para desvendar os labirintos do campo parlamentar português. 


\section{Do abstrato ao concreto: A etnografia enquanto alternativa epistemológica}

A abordagem etnográfica que aqui se propõe surge como alternativa epistemológica às perspetivas hegemónicas que moldam os discursos sobre o Estado e a representação política. Por um lado, esta abordagem permite contrariar o duplo-vício que consiste em analisar o Estado de forma monolítica a nível macro (atribuindo-lhe sempre a mesma identidade, como se a ação nas instituições não se refletisse em posicionamentos historicamente variáveis e dependentes de vários desdobramentos institucionais) e de forma simplista a nível micro (como se fosse possível conhecer o Estado sem olhar para a diversidade pessoas e interações que garantem o funcionamento das suas instituições). Por outro lado, ela constitui também uma alternativa às abordagens académicas que, de um ponto de vista, ocultam tanto quanto revelam, sempre que se debruçam sobre este complexo objeto.

Uma dessas abordagens é a corrente jurídica, normativa e abstrata, que analisa as instituições, a partir dos textos legais e normativos que abstratamente as enquadram e organizam. Evidentemente, a longa tradição da sociologia e antropologia jurídicas (Ferrari, 1990; Kuppe e Potz, 2005; Latour, 2002; Luhmann, 2004), também em Portugal (Ferreira e Pedroso, 1999; Lopes, Frois, Mineiro, Carvalheira, Gomes Moreira e Bento, 2017), adverte-nos que as leis, os códigos e os regulamentos, sendo formulações abstratas, devem ser analisados a partir das suas dissonâncias, tensões e conflitos com as práticas concretas das sociedades, dos grupos e dos indivíduos.

Se nos centrássemos exclusivamente no enquadramento normativo, facilmente assumiríamos que os deputados estão em igualdade de circunstâncias. Todos eles, regimentalmente, têm os mesmos direitos, deveres e funções, independentemente de serem homens ou mulheres, do litoral ou do interior, de círculos com maior ou menor representatividade, com mais ou menos escolaridade, de profissões mais ou menos qualificadas. Mas será que todos os deputados têm os mesmos poderes²? Estudar uma instituição política exclusivamente a partir deste enquadramento impedir-nos-ia de compreender como é que estes são apenas direitos formais, sendo a sua interpretação bem mais complexa na vida quotidiana.

Uma segunda perspetiva da qual esta pesquisa se distancia é aquela que tende a assumir, explicita ou tacitamente, dentro da academia e fora dela, que os deputados fazem parte de um grupo social homogéneo mais amplo, que pode também assumir o nome de "políticos" ou de "classe política". Entrar nos corredores do Parlamento, procurando conhecer quem ali circula, mostra-nos que não há nenhuma razão sociologicamente válida que nos permita agrupar os 230 deputados num grupo social unificado. As suas trajetórias de vida são distintas, as suas pertenças 
sociais também, mesmo que, como se verá, haja características sociais e culturais dominantes.

A etnografia, enquanto alternativa epistemológica, mostra como determinadas origens sociais e trajetórias biográficas potenciam (ou inibem) a possibilidade de acesso, adaptação e permanência num mundo institucional onde dinâmicas entre pares seguem normas muito particulares. No entanto, assumir uma visão homogénea dos deputados portugueses, torná-los-ia invisíveis: o discurso genérico facilmente descairia para o estereótipo e para a reprodução de lugares-comuns, contribuindo para a produção de um discurso sobre o poder assente em representações parcelares. O trabalho de campo etnográfico busca o exercício diametralmente oposto.

\section{Uma etnografia da Assembleia: Métodos e técnicas de investigação}

Esta pesquisa centrou-se na realização de uma etnografia do Parlamento português, desenvolvida entre outubro de 2015 e julho de 2018, através da qual foi possível observar, conversar, entrevistar ou acompanhar o trabalho dos indivíduos que aí interagem diariamente. Procurou conhecer-se o "como" se pensa aquilo que se faz, na tentativa de compreender os passos que indivíduos dão para concretizar determinadas ações (Becker, 1998). É como desvendar um puzzle (Mason, 2012), em que é preciso superar enigmas para tentar completar a imagem, através de um misto de ciência e arte (Tilly, 2007; Woods, 1986). A etnografia torna-se, portanto, um método de investigação, e um conhecimento decorrente da sua aplicação (Lopes, Frois, Mineiro, Carvalheira, Gomes Moreira e Bento, 2017, p. 21), geralmente pouco aplicado a contextos de prática política (Joseph, Mahler e Auyero, 2007), facto que esta pesquisa procura também contrariar. Um método em que nos expomos perante uma apresentação do eu que, como afirma Catarina Frois, é "permanente equacionada e negociada, sem que tal signifique que há uma contradição nos termos. Em diferentes contextos os indivíduos expõem, ocultam, revelam e manipulam a forma como se apresentam aos outros" (Frois, 2017, p. 30). Por isso, parece-me importante que a etnografia se desdobra numa multiplicidade de técnicas de investigação, mobilizadas contextualmente, mediante cada oportunidade, interação ou agente com qual se interage. Por isso, esta é uma abordagem metodologicamente diversa.

a) A observação de espaços formais e não-formais de interação tem uma grande centralidade. Por 'observação' entendo o acompanhamento de uma determinada situação de interação, durante um período suficientemente prolongado para que se tornem claras as posições em jogo, as dinâmicas de interação, as 
suas regularidades e a sua cadência. Este trabalho de observação pode denominar-se de participante ou não participante, consoante haja ou não uma interação direta e verbal entre o etnógrafo e os atores observados. Parte das sessões de observação realizaram-se em espaços internos da instituição (reuniões plenárias, comissões parlamentares, corredores, bares, cantinas, salas de trabalho, entre outros) e outra parte ocorreu fora da instituição (visitas aos círculos eleitorais, deslocações ao exterior da Assembleia, interações em bares e restaurantes, entre outros).

b) Neste contexto da observação destaca-se a realização de job shadowing etnográfico, isto é, um tipo de observação que implicou o acompanhamento do dia-a-dia de trabalho de determinadas pessoas. Foi possível acompanhar, durante uma semana, as atividades de um Presidente de um Grupo Parlamentar, da vice-presidente de outro Grupo Parlamentar e ainda de um deputado e Presidente de Comissão Parlamentar. Além disso, dois deputados permitiram o acompanhamento de um dia inteiro do seu trabalho, tendo ainda sido possível o acompanhamento de uma semana de uma sala de assessores de um partido e duas semanas de trabalho de assessores parlamentares da Assembleia da República.

c) A realização de entrevistas semidirigidas ou não-dirigidas, revelou-se igualmente fundamental já que permitiu interagir com um grande número de pessoas, com papéis sociais distintos e em diferentes contextos. No total realizaram-se 134 entrevistas - 83 a deputados de todos os partidos representados; 26 a assessores dos grupos parlamentares; 11 a jornalistas de jornais, rádio e televisão; 9 a assessores e funcionários parlamentares; 5 a profissionais de agências de comunicação.

d) As conversas etnográficas ou informais em espaços dentro e fora da instituição são igualmente um método que decorre da etnografia, mas que autonomizo por dois motivos: primeiro, porque as conversas, em contexto etnográfico, devem emergir de relações intersubjetivas e empáticas que têm de se estabelecer no quotidiano da instituição; depois, porque estas conversas, mesmo que ocorrendo em espaços de fronteira (corredores, bares, salas de espera...), se devidamente orientadas e pensadas, permitem conhecer muitos dos pormenores da vida institucional.

e) Neste contexto, optou-se pela realização de retratos biográficos e narrativas de vida, em casos cujas relações de proximidade e empatia o permitiram.

f) Organizou-se, igualmente, uma base de dados estatística, a partir de fontes secundárias, que permite uma ampla caracterização sociodemográfica dos deputados portugueses. 
g) A pesquisa etnográfica permitiu, ainda, entrar neste mundo social por via do acesso a documentos oficiais, internos e de trabalho. Para isso realizou-se uma análise de conteúdo de diversos tipos de documentação - material legislativo, diários das sessões ou regulamentos internos.

h) A pesquisa beneficiou, ainda, de uma dimensão de análise etnográfica do mundo virtual, observando-se a presença de deputados nas redes sociais e na imprensa, à medida que igualmente acompanhava o seu trabalho quotidiano.

Esta abordagem plural permitiu a obtenção de uma grande variedade dados. Neste artigo irei dar conta de parte deles, analisados a partir de um ângulo específico: o da relação entre as características sociais dos representantes políticos, as suas práticas e representações quotidianas e os lugares de poder que essas características e essas práticas engendram. Este ângulo de análise parte do conceito de "classe soci$\mathrm{al}^{\prime \prime}$, tal como ele foi equacionado interseccionalmente por Pierre Bourdieu (1979), isto é, tentando compreender as determinantes sociais e culturais que se configuram pela posse e distribuição de diversos capitais, que igualmente se refletem em distintas atitudes, interesses, práticas e tomadas de posição.

\section{Quem são os/as deputados/as portugueses?}

Os deputados portugueses candidatam-se em listas plurinominais, sendo eleitos por sufrágio universal, a partir de círculos eleitorais. São 230 as pessoas a quem cabe representar o conjunto do país, legislar, fiscalizar o Governo e a administração pública, entre outras funções. Mas quem são, afinal, estas pessoas que, em nosso nome, decidem o nosso futuro?

A leitura mais comum consiste em agrupá-los consoante as suas filiações partidárias, formalmente expressas na sua inserção por grupo parlamentar, geralmente associado a um partido político.

A opção por um sistema de representação proporcional por círculos eleitorais, conjugada com a conversão de mandatos pelo método da média mais alta D’Hont, como referem Maria Leitão e Nuno Santos e Silva (2008, p. 17), reside nas eleições para a Assembleia Constituinte em 1975, onde na proposta de lei eleitoral se defendia que a assembleia "deveria ser a imagem do eleitorado, reflectindo, na medida do possível, as suas correntes de opinião e tendências políticas realmente significativas. Ora só a representação proporcional satisfaz este objectivo"3.

Nesta XIII legislatura parlamentar há sete partidos políticos representados: 89 deputados do PSD; 86 do PS; 19 do BE; 18 do CDS; 15 do PCP; 2 do PEV; 1 do PAN. Entre os deputados que exercem funções até junho de 2018, houve 20 que 


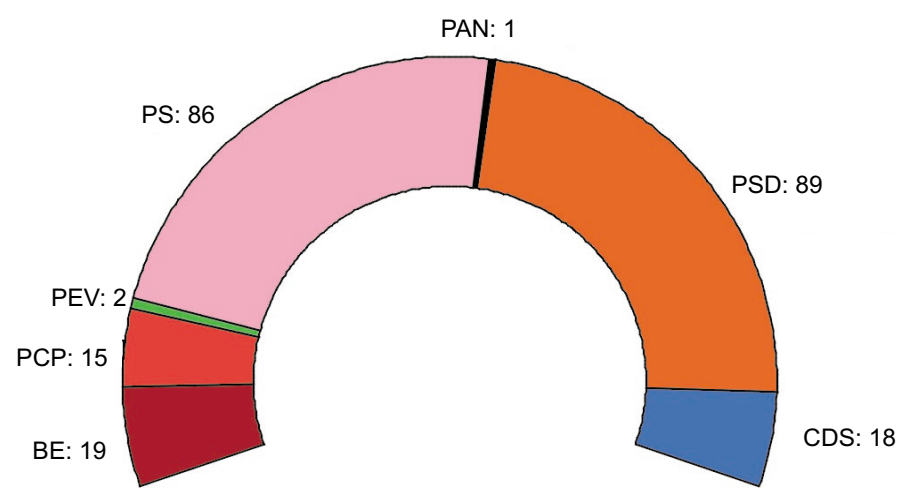

Figura 1 Distribuição dos deputados por partidos políticos representados Fonte: Assembleia da República.

eram filiados nos partidos pelos quais foram eleitos. Mas para conhecer o corpo de representantes é necessário adicionar às diferenciações partidárias, outros fatores de diferenciação social.

Olhando para a diferença entre homens e mulheres à data das eleições de outubro de 2015, percebemos que os homens estão em maioria. No entanto, em termos diacrónicos, percebemos também como a presença das mulheres tem vindo a aumentar: 6 \% em 1980; 20\% em 2002; 34\% em 2015. Uma análise exclusivamente quantitativa poderia sugerir uma inversão da hegemonia masculina na representação política. Mas, mais uma vez, é preciso cuidado com os dados.

Com efeito, quando acompanhamos o trabalho na Assembleia da República, percebemos que este é um mundo altamente hierarquizado. Sendo um dos vértices dessas hierarquias os lugares de autoridade nos grupos parlamentares, fui perceber quem domina estes órgãos internos, concluindo que apesar dos homens representarem $66 \%$ do total parlamentares, o número é bem diferente no que se refere aos cargos de direção hierárquicas: $70 \%$ das direções dos grupos parlamentares são compostas por homens; $71,9 \%$ nas coordenações de Comissão; e 75\% nas presidências de comissões. A dominação masculina do mundo parlamentar, particularmente no que se refere à condução política quotidiana, é ainda bastante estruturante da ordem parlamentar.

Acompanhar os trabalhos parlamentares obriga-nos a conhecer códigos, regulamentos, siglas, expressões, conceitos, formas de organização complexas. No trabalho de campo foi muito óbvio o que Lave e Wenger (1991), na moderna teoria organizacional, designam por comunidades de prática e aprendizagem situada ${ }^{4}$. 


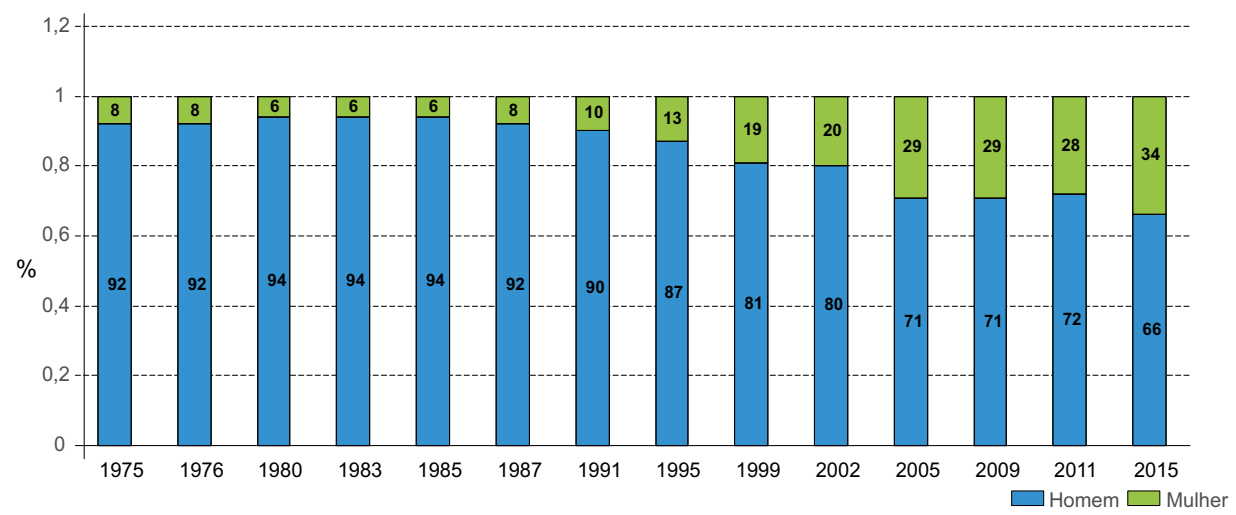

Figura 2 Diferença de sexo entre os deputados portugueses

Fonte: Assembleia da República.

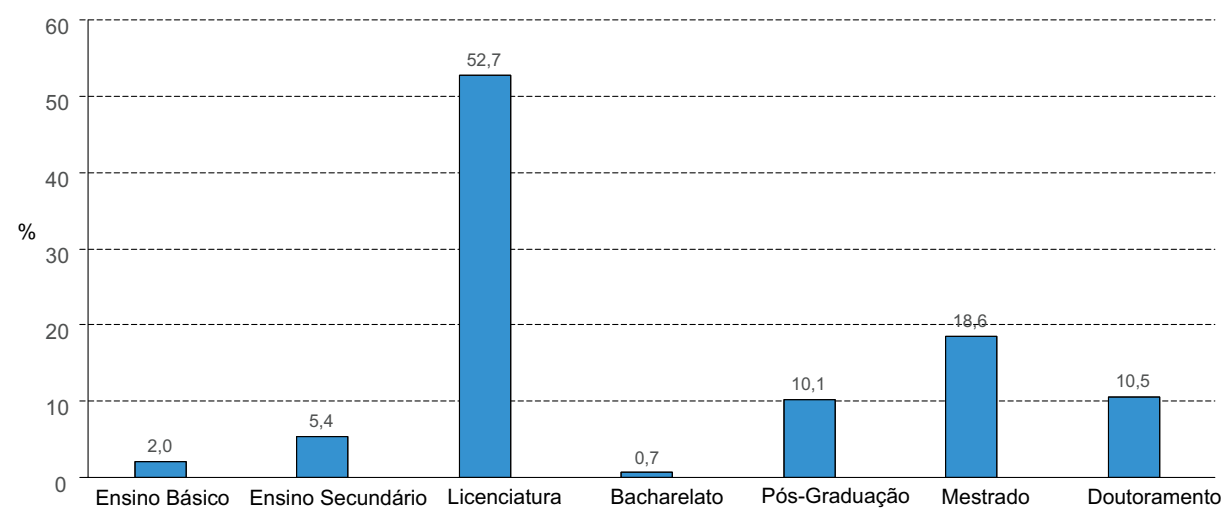

Figura 3 Graus de escolaridade dos deputados portugueses

Fonte: Assembleia da República.

Aceder à comunidade de prática parlamentar, implica a absorção de um conjunto de aprendizagens situadas. E esse processo mostra-nos como o Parlamento é um mundo burocratizado e tecnicizado, onde o debate, a produção legislativa e as interações constituem processos relacionais marcados pela mobilização de conhecimento técnico e hiperespecializado, através de uma linguagem codificada e autorreferencial. Daí que a esmagadora maioria dos deputados - mais de $90 \%$ - tenha um nível superior de educação completo, quase $20 \%$ já tenha concluído o seu mestrado e mais de $10 \%$ o doutoramento. 
Esta característica reflete-se nas próprias áreas de formação. Dos deputados que exerceram funções entre outubro de 2015 e julho de 2018, 98 deles eram formados em direito (cerca de 33\%); 30 deles eram formados em economia (10\%); 20 formados em engenharias (7\%); e 18 deles em gestão (cerca de $6 \%)^{5}$. A dominância destas áreas é reveladora de um perfil de recrutamento parlamentar muito assente no direito, relacionado com o facto da produção legislativa ser uma das funções primordiais da Assembleia e exigir uma preparação técnica particular. Mas também são relevantes as formações de economia e gestão, particularmente num contexto em questões económicas, financeiras e orçamentais têm peso decisivo e estruturador de todas as outras políticas públicas. Estas características refletem-se também nas profissões de origem dos deputados.

Como se percebe, há uma clara dominância de quem era advogado ou jurista antes de chegar à função, seguindo-se os professores, economistas, gestores e engenheiros ${ }^{6}$, sugerindo um perfil de recrutamento muito assente em profissões liberais que se adequam ao tipo de socialização política e cultural que parece esperado que ali ocorra.

Apesar da diversidade de círculos eleitorais, ao analisarmos a naturalidade dos deputados constatamos que mais de $37 \%$ dos deputados eleitos são naturais de Lisboa ou do Porto, chegando a mais de $60 \%$ se contarmos com os distritos Braga, Aveiro e Coimbra. Ou seja, a representação política acompanha a tendência de concentração populacional nos grandes certos. Num contexto de perda de população dos distritos menos populosos do interior do país, estes perdem também deputados elegíveis, contribuindo para uma crescente "litoralização" da representação política e do país7.

Uma última característica a assinalar é o facto de grande parte dos deputados portugueses ter ou já ter tido outro tipo de experiências de participação política institucional. Quase um quarto deles - $23 \%$ - já teve experiência governativa antes do cargo, e a esmagadora maioria - cerca de $80 \%$ - já teve experiência autárquica. Treze deles também já teve experiência europeia. Os deputados inserem-se, portanto, em lógicas de polienvolvimento político, fazendo da política uma parte do seu percurso profissional. É por isso que 124 deputados desta legislatura tenham sido também candidatos nas eleições autárquicas de 2017, 104 deles acumule o mandato parlamentar com outros mandatos locais, e 29 já tenham sido também presidentes de câmaras municiais8.

Todos estes dados nos dão pistas para pensar quem social e culturalmente domina o exercício da representação política. Mas elas não são autoexplicativas, já que é na prática, nos contextos imediatos de ação, que é possível desvendar as determinantes sociais, económicas ou culturais que se constituem como fatores de 


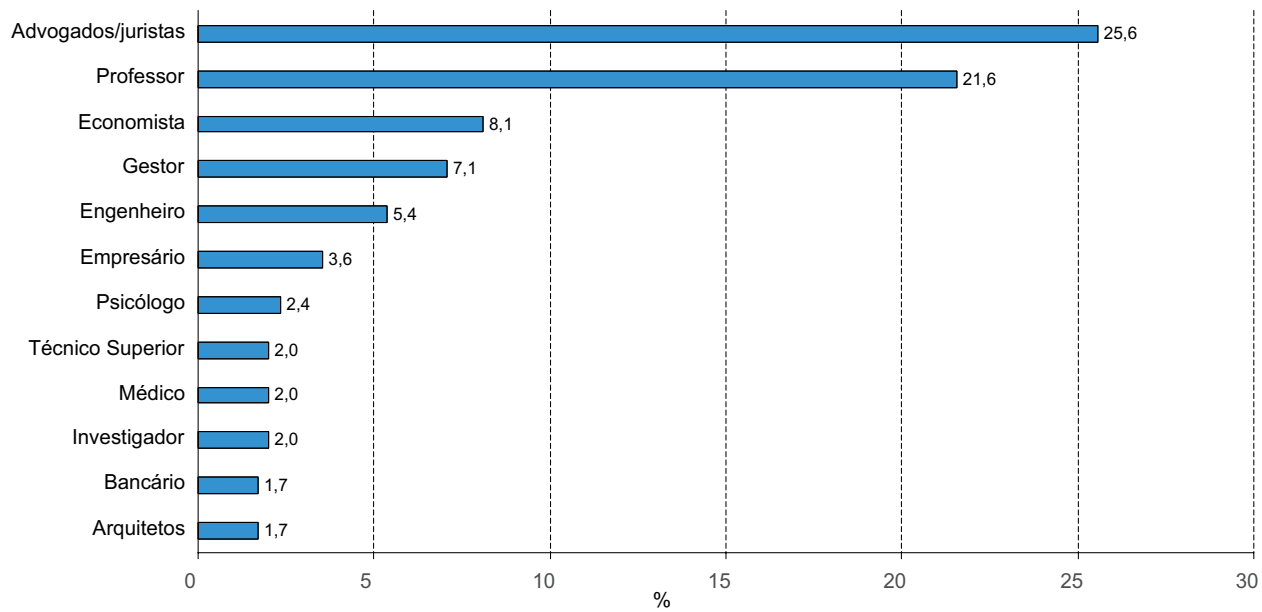

Figura 4 Profissões de origem dos deputados portugueses

Fonte: Hemiciclo.

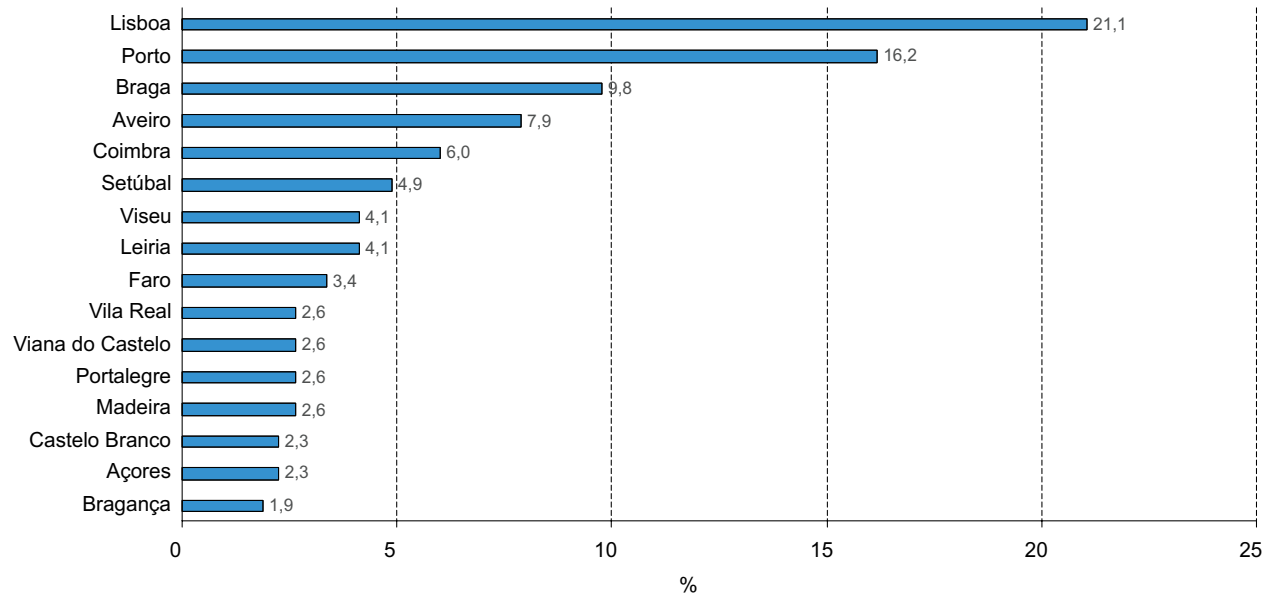

Figura $5 \quad$ Naturalidade dos deputados portugueses

Fonte: Hemiciclo.

agencialidade ou inibição política. Para pensar esta relação, assinalam-se cinco tipos-ideais de deputados, que ilustram diferentes trajetórias de acesso e adaptação ao campo parlamentar. 


\section{Os aprendizes}

Um terço dos deputados da presente legislatura exercem pela primeira vez o seu mandato. Pedro foi um desses casos ${ }^{9}$. A sua vida mudou muito desde que chegou à Assembleia. Suspendeu temporariamente os estudos, passou a viver numa outra cidade e aumentou o seu investimento de tempo no partido. A sua chegada não foi isenta de alguma surpresa. "Isto é enorme", dizia-me enquanto caminhávamos pelos corredores do 2 . $^{\circ}$ piso, para depois confessar que "sente-se que o poder circula aqui dentro". A sua inserção no mundo parlamentar não foi simples. "Tive de me adaptar, não é?", explica-me, exemplificando que teve de mudar o guarda roupa, treinar o tom de voz para estar mais adequado, experimentar soundbites, testar discursos para diferentes públicos, mudar as suas contas nas redes sociais ou aprender a controlar o que se deve revelar aos jornalistas.

José foi também um deputado que chegou ao Parlamento quando ainda era estudante universitário ${ }^{10}$. Já com alguma experiência disse-me que todos estes sentimentos de estranheza passam rápido. Para aqueles para quem "depois da universidade é direto", a habituação é fácil e rápida porque o partido está declaradamente a investir no seu futuro político. Chamam-se a este investimento ter uma "política de quadros". Segundo este deputado, os novatos, se querem ficar no Parlamento, têm de ser prudentes e cautelosos. E o que significa ser prudente? Respondeu, a sorrir, que "um jovem quadro cedo se apercebe do que deve fazer" para garantir que fica nas listas futuras: rodear-se de pessoas com influência no partido e no Parlamento; manter e reforçar um grupo de apoio entre militantes de base; não desafiar diretamente as autoridades internas, mas impor a sua presença com subtileza; fazer uma gestão inteligente do seu posicionamento perante os conflitos que surgem. O primeiro mandato é uma espécie de teste. Para quem a experiência é positiva, o futuro na instituição pode ser promissor, tornando-se bastante híbrida a relação entre a trajetória política e o percurso biográfico.

\section{Políticos com a chave de carro no bolso}

Ao contrário dos novatos, muitos deputados cujo trabalho acompanhei já estavam há várias décadas no Parlamento. Para eles, a atividade política tem sido a sua ocupação permanente. Um desses casos foi o de Rui11. Chegou a Lisboa aos 17 anos para estudar direito, ainda na década de 70. Num país com um baixo nível de qualificações, logo que acabou o curso foi recrutado para o seu primeiro cargo político: as suas competências técnicas na área do direito e a sua ligação a uma juventude partidária tornavam-no "um ótimo quadro político". Tinha pouco mais de 20 anos. Desde esse momento, toda a sua vida foi preenchida por cargos políticos: assessor, 
deputado numa assembleia legislativa regional, secretário de Estado, ministro, eurodeputado. "Fui tudo o que quis", diz-me, com um sorriso orgulhoso, enquanto almoçávamos no restaurante do Edifício Novo da Assembleia da República.

No entanto, nas várias conversas que tivemos, insistiu que "a política não é uma profissão" porque "quem anda na política deve ter sempre um lugar de recuo". Por isso, diz-me: "a minha profissão é ser político com a chave do carro no bolso"; "a vida política é precária", "é um contrato ao dia".

Esta era uma opinião partilhada por Ricardo ${ }^{12}$, que se estreou no Parlamento na década de 80, com pouco mais de 20 anos. Desde aí, a atividade política tem sido a sua profissão. Mas foi muito contundente quando me disse: "Eu não gosto desse conceito de classe política. Eu acho que não há, nem deve haver, uma classe política". Considera-se "orgulhosamente um professor", apesar de não exercer essa profissão há mais de 30 anos. Quando o tema da nossa conversa remete para o futuro, o seu discurso certo e incisivo dá lugar a um tom mais hesitante: "Eu hoje ia ter um problema terrível. A minha disciplina já mudou duas vezes desde que eu saí; ia ter um problema terrível para me readaptar".

Casos como o de Rui e Ricardo, colocavam um problema imediato que encontrei em muitos outros deputados: por um lado, praticamente toda a sua trajetória laboral foi desenvolvida no Parlamento ou noutros cargos políticos; por outro, continuam a identificar-se com as suas profissões de origem.

Ao contrário da língua alemã em que Beruf trata de designar, simultaneamente, "profissão" e "vocação" - termo aliás usado por Max Weber (2000) para falar da política como profissão/vocação - , na língua portuguesa essas duas palavras têm significados bem distintos. É por isso que muitos deputados distinguem o que consideram ser uma "carreira profissional" e um "cargo político" que se exerce por vocação e que deve ser transitório.

Talvez uma investigação exclusivamente centrada numa ronda de inquéritos ou entrevistas dirigidas ficasse por aqui. Mas apoiando-nos numa pesquisa etnográfica, ela permitiu que observássemos, ao longo do tempo, a relação entre discursos e práticas, projeções abstratas e confrontos com o quotidiano, ideias que se tomam como ideais e contingências que decorrem do dia-a-dia. É por isso que não foram poucas as vezes que se identificou aquilo que Goffman designava de "faux pas" (1993).

Esses "passos em falso", sendo ruturas involuntárias com as projeções ideais das representações, não querem dizer, necessariamente, que haja uma manipulação do discurso. Significam, antes, que pode haver uma dissociação entre as ideias que se tomam por ideais, e a realidade concreta da vida quotidiana. Uma deputada dizia-me numa ocasião que "ser deputada não é uma profissão, mas um cargo que 
se pode deixar de exercer a qualquer momento", e noutro momento, quando falamos sobre quais as características de um bom parlamentar, referia "faz parte da profissão ser um bom orador". Profissão, essa, que para ser bem exercida implica um trajeto de vida ascendente na instituição, muito semelhante a qualquer outra carreira profissional. A dissociação entre o que se diz e o que se faz, sugere um facto revelador sobre a relação de vários deputados com a função: é que ao mesmo tempo que parecem recusar a associação da atividade política a uma profissão, nas suas práticas e discursos deixam transparecer uma relação profissionalizada com a função.

\section{Gradualistas}

Chamemos gradualistas aos deputados que se encontram numa posição intermédia entre os novatos (ainda em processo de adaptação) e os profissionais (já bastante estabelecidos nas hierarquias de partido). São deputados cuja trajetória de vida se vai conectando com a trajetória partidária, percorrendo gradualmente os diversos lugares que estruturam a sua organização. Maria é um desses casos. A sua família era bastante envolvida politicamente, especialmente o pai, "já que as mulheres assumiam papéis mais de sombra". A forte politização na família originou uma socialização em torno de objetos, conversas e símbolos políticos.

Começou aos 15 anos a envolver-se numa juventude partidária, assumindo atividades ligadas ao ensino básico e secundária: “O meu pai ficava orgulhoso pelos materiais que trazia para casa", diz-me, igualmente com um sorriso orgulhoso. Aos 18 anos foi convidada para ser dirigente no concelho e pouco depois no distrito. Enquanto a sua militância crescia, foi fazendo o seu curso no Ensino Superior, tendo depois começado a trabalhar na área. A experiência não correu bem e foi convidada para ser funcionária política. Aceitou, já que "vivia muito intensamente a atividade do partido". Nessa altura entrou também para a direção nacional. "Ao longo dos anos comecei a ficar saturada da repetição do trabalho", diz-nos, explicando que surgiu então a oportunidade de chegar a assessora do grupo parlamentar. Uma atividade "que permitiu um conhecimento mais real do Parlamento e da luta política". Durante esses anos, ganhou competências técnicas de interpretação de leis, dados e linguagens relacionadas com o jogo político-parlamentar. Foi então que conseguiu conquistar um lugar nas listas candidatas, o que lhe permitiu chegar a deputada. Metade do caminho estava percorrido.

O caso de Maria é quase uma cópia de Cristina, apesar de se encontrarem em partidos muito diferentes. Antes de chegar a deputada já tinha tido um percurso profissional dentro do partido. Para os deputados com este perfil, esse percurso 
permite-lhes ter um conhecimento e domínio do "sentido de jogo": as regras escritas e não-escritas; a organização e o funcionamento; os códigos e as lógicas de atuação. Como nos diz: "Antes de ser deputada já conhecia muito bem o Parlamento, muito bem mesmo. Não fui daquelas pessoas que vem para aqui 'descobrir'. Eu conhecia muito bem o Parlamento e vir para aqui trabalhar não foi propriamente um acaso, foi uma coisa que eu procurei."13

Mas a sua trajetória gradual não se circunscreveu à transição funcionária-assessora-deputada. A partir do momento em que chegou a deputada começou uma segunda etapa: primeiro, foi necessário ganhar autonomia, expressão e influência dentro do grupo parlamentar; depois, assumir funções de coordenação em comissões parlamentares; por fim, chegar à direção do partido e do grupo parlamentar. Foi um percurso gradual e paulatino, resultado de "muito trabalho" e de "várias aprendizagens".

\section{Deputados-técnicos}

Temos falado de trajetórias de vida com uma relação umbilical com percursos políticos e partidários. Mas há deputados com um perfil diferente, tendo uma longa experiência profissional antes da função parlamentar. É o caso de Teresa, eleita pela primeira vez em 2015. Com um longo percurso no mundo empresarial e académico, Teresa sentiu uma "crise existencial e vocacional tardia", que a levou a procurar na política uma saída. O facto de Teresa ter chegado ao Parlamento sem uma experiência político-partidária prévia, levou-me a antecipar a existência de um handicap, já que a inserção num partido implica a capacidade de adaptação a regras não-escritas, que se aprendem ao longo de anos de militância. No entanto, durante os primeiros meses, percebemos que tal não aconteceu: a deputada falava regularmente no plenário e em comissões, passando a ter uma expressão pública regular. Apesar da sua pouca experiência partidária, Teresa teve uma adaptação rápida às engrenagens, o que se deveu, entre outros aspetos, às suas elevadas qualificações, ao seu perfil profissional e a uma capacidade técnica desenvolvida anteriormente. O capital cultural legítimo, mais que o capital social, revelou-se um importante fator de agencialidade.

Esse foi também o caso de João. O deputado, igualmente pela primeira vez no Parlamento, tinha um forte handicap: pertencia a um grupo interno minoritário no seu partido, não tendo relações de forte cumplicidade política com a direção do grupo parlamentar. Teria teoricamente uma maior dificuldade em afirmar-se, facto que ele próprio nos antecipou. Nos primeiros meses sentava-se discreto nas últimas filas do hemiciclo. Mas foi com algum espanto que quanto mais tempo passava mais ele se aproximava das primeiras filas. Começou, passados alguns meses, a intervir em nome no partido, depois a coordenar a intervenção em comissões 
parlamentares, tornando-se em pouco mais de um ano num dos deputados com maior destaque do seu grupo.

Para este parlamentar foi muito fácil desencriptar o sistema. Desde os primeiros meses que se moveu como um profundo conhecedor das lógicas parlamentares. A sua experiência profissional dava-lhe um conhecimento aprofundado das matérias com que lidava e igualmente as capacidades oratórias para intervir numa grande plateia como é o plenário. A visibilidade mediática que anteriormente lhe era concedida através da participação em programas de debate televisivo, confirmava o seu capital simbólico perante os pares. Como nos relatou:

Desde o "cavaquismo" que a discussão tecnocrática na política se impôs. E quando a discussão tecnocrática se impõe, é muito difícil participar sem qualificações. As pessoas muito qualificadas são mais ouvidas quando é preciso formar opinião. É importante ter formação superior ou ser considerado profissionalmente. Eu tinha uma vantagem competitiva à partida, era um tipo considerado porque emitia opinião sobre alguns assuntos relevantes e atuais... E, portanto, isso dava-me uma vantagem face à rapaziada que andava lá, basicamente, numa lógica diferente, mais bandeiras e cartazes. ${ }^{14}$

Estes são casos de deputados que acentuam muito o "caráter técnico" da sua intervenção. As suas qualificações e percurso profissional permitem-lhes uma adaptação, sem grandes constrangimentos, a um sistema parlamentar que ao longo dos anos se tecnocratizou. Como sintetizava uma outra deputada, professora universitária:

Há deputados que vão estar mais próximos da relação com o distrito. Há deputados que vão estar mais próximos da gestão da vida política, porque é o que eles fazem bem. E depois há deputados, que é onde eu talvez me insira mais, que acabam por ser mais técnicos, que é onde eu me insiro mais. Eu tipicamente contribuo mais para o debate do ponto de vista técnico e de economia e de pensar políticas, está a ver? ${ }^{15}$

O processo parlamentar transforma o debate político, e sobretudo a produção legislativa, em processos relacionais marcados pela mobilização de conhecimento técnico e hiperespecializado, através de uma linguagem codificada, que só pode ser eficazmente compreendida por "especialistas" detentores de formação académica e profissional elevada (Lopes, Frois, Mineiro, Carvalheira, Gomes Moreira e Bento, 2017). A conjugação entre inserção nas engrenagens hierárquicas dos grupos parlamentares e a mobilização de competências técnicas, permite aos deputados um conhecimento preciso do "sentido de jogo", isto é, um "sentido prático", das regras escritas e não-escritas, da organização formal e informal, dos códigos e 
das lógicas de atuação, enfim, "do universo das técnicas de acção e de expressão que ele oferece em dado momento" (Bourdieu, 2011, p. 170).

\section{Os delegados distritais}

Como vimos, a grande maioria dos deputados tem experiência autárquica, uma parte deles já foram presidente de câmara e mais de metade foi candidato autárquico nas eleições autárquicas de 2017. Tal como noutros países (Abélès, 2000; Crewe, 2015), a circunstância do deputado ser eleito por círculos eleitorais locais, faz com que as organizações locais dos partidos tenham um importante papel na composição de parte das listas e na permanência de certas pessoas na instituição. E isso cria, em alguns deputados, uma distinta forma de pensar a representação política.

Apesar da lei determinar que o deputado "representa o país no seu conjunto" e "exerce o mandato livremente", muitos deputados sentem-se como "delegados distritais", isto é, mandatários do distrito que os elegeu e dos seus eleitores e organizações. Isso manifesta-se na prática quotidiana. O seu trabalho não se centra na feitura das leis ou no debate público. Pelo contrário, eles tentam colocar temas do seu distrito na agenda e fazer uma comunicação desse trabalho diretamente com os órgãos de comunicação locais, entidades locais e do distrito e nas redes sociais. Um deles disse-me mesmo que se consideravam "uma espécie de comunidade de expatriados", arredados dos circuitos fechados dos deputados eleitos pelos círculos mais representativos ou com mais poder mediático.

\section{Peixes fora de água}

Falou-se aqui de deputados com longa experiência parlamentar, dos que tiveram uma inserção gradual e dos que se adaptaram facilmente pelo capital cultural legítimo que possuíam antes da função. Mas sendo o Parlamento um lugar diverso, também pudemos conhecer casos diametralmente opostos.

Luísa foi um desses casos. Nunca pertenceu ao partido pelo qual foi eleita. Nas conversas que tivemos percebemos que havia uma grande distância entre a sua atividade e a da maioria dos deputados que tinha acompanhado. O seu conhecimento sobre a sua forma de organização interna do grupo parlamentar e do partido era praticamente inexistente. Contava-me que quando a convidaram para as listas não levou a sério e pensou que era "para fazer número". Acabou por ser eleita e caiu de paraquedas na instituição.

Luísa fazia parte daquele conjunto de deputados que chegam ao Parlamento sem previamente conhecerem o sistema, o seu funcionamento e organização, as suas regras, usos, rotinas e convenções. Para ela, como para muitos outros, o 
sentimento de desencontro face à instituição foi absoluto. A ausência de enquadramento prévio na estrutura do partido, a inexistência de apoio direto e individualizado aos deputados e as fracas qualificações, tornaram muito difícil o domínio das lógicas de funcionamento. Como nos diz numa das nossas primeiras conversas: "Sou como um peixe a nadar fora de água e a tentar orientar-se". Foi tentando, sim, mas acabou por deixar o Parlamento dois anos depois da eleição.

O sistema parlamentar e a organização dos partidos políticos são estruturas construídas para (e por) quem tem uma grande participação partidária prévia ou, pelo menos, uma formação académica ou profissional que lhe permita integrar um edifício burocrático complexo em que as dinâmicas entre pares seguem normas muito particulares de funcionamento. Para quem chega sem um certo enquadramento partidário, os grupos parlamentares, e a instituição em si mesma, podem tornar-se universos simbólicos de morosa absorção e descodificação. Para usar uma metáfora teatral, estes espaços tornam-se verdadeiros palcos com as suas estrelas e os seus habitués. Para quem sempre esteve na plateia a assistir ao espetáculo, não é fácil ultrapassar a quarta parede.

\section{A ação política nos labirintos hierárquicos}

Para além das trajetórias biográficas dos sujeitos, há outras dimensões cruciais para compreender a agencialidade política no Parlamento. Uma das mais importantes é a forte hierarquização interna do trabalho político-parlamentar. É certo que a legislação garante, abstratamente, que o deputado exerce livremente o seu mandato. Mas o que a etnografia nos mostra é que, na prática, é impossível compreender a ação individual dos eleitos, sem as enquadrar na estrutura das suas hierarquias internas.

As hierarquias assumem diferentes configurações consoante a cultura partidária, a dimensão do grupo parlamentar ou a relação com o Governo. Ainda assim, em todos os grupos parlamentares, a hierarquização funciona como um mecanismo de constrangimento ou de agencialidade, consoante a posição relacional que cada deputado ocupa face à estrutura de autoridade. A importância destas hierarquias é tal que a primeira tarefa política dos deputados eleitos é a escolha do líder parlamentar, da sua equipa de direção, dos presidentes de comissão parlamentar e dos coordenadores e vice-coordenadores dos partidos nas comissões. Só quando a estrutura é montada é que o sistema está pronto a funcionar. Para além disso, tão importante como as hierarquias formais, diz-nos uma deputada, "é aprender as hierarquias informais", isto é, aquelas que dizem respeito à precedência, antiguidade, peso simbólico, relação com o sistema mediático e com a estrutura de assembleia. 
A condução política dos grupos parlamentares é feita a diferentes níveis consoante estes sejam mais ou menos centralizados e conforme o partido tenha mais ou menos eleitos. No topo da hierarquia parlamentar está, invariavelmente, o presidente do grupo parlamentar, e a sua direção, constituída por um conjunto de vice-presidentes. O "líder parlamentar", como esta figura é conhecida, é o representante máximo do grupo, sendo cuidadosamente escolhido tendo em conta a geometria do debate interno de cada partido. Como nos diz um deles:

O exercício ininterrupto de líder parlamentar é de facto um trabalho muito especial. Porquê? Porque é um trabalho que tem a ver com a definição política das posições do partido, tudo gravita em volta daquilo que o líder parlamentar, com a sua equipa de direção, vai articulando com a direção do partido. É coordenar o trabalho de todos os deputados. É definir o que é que cada um faz, quando faz e como faz. ${ }^{16}$

O líder parlamentar é o pivô de um dos vértices das hierarquias parlamentares: ele coordena e vigia o trabalho dos deputados, antecipa problemas, distribui funções consoante as sensibilidades do grupo e articula a intervenção parlamentar com as posições do partido fora do Parlamento. É, portanto, um elo de ligação fundamental com outro vértice hierárquico: a liderança do partido, cuja orientação política se deve refletir nas posições assumidas pelos deputados do grupo parlamentar.

A autoridade da liderança é desenvolvida por um conjunto de deputados que são vice-presidentes da bancada e que ficam responsáveis por áreas específicas de atuação. Cada vice-presidente coordena o trabalho nas comissões, influencia a escolha dos oradores em plenário, acompanha os dossiês principais, controla o trabalho feito e antecipa problemas que podem surgir. A terceira linha da pirâmide corresponde aos coordenadores de comissão parlamentar. São deputados responsáveis pela função de alavancarem o trabalho do partido em cada comissão especializada. Identificam prioridades políticas, organizam o trabalho e distribuem-no pelos deputados.

Entre o líder parlamentar, os vice-presidentes e os coordenadores da comissão, encontra-se o núcleo de deputados que centraliza a atuação e definição política dos grupos parlamentares. Esta estrutura dirigente é composta por deputados capazes de ativar uma rede de relações prévias construídas em longos percursos partidários e que lhes garante autoridade política. Talvez por isso, João, um deputado recém-chegado, nos diga o seguinte:

As lideranças políticas cultivam a pouca autonomia dos deputados. Porque quando tu eleges oitentas, ou cem ou não sei quantos, como o meu partido já elegeu, a 
liderança política determina o trabalho. Tens uma liderança de um grupo parlamen$\operatorname{tar} \operatorname{com} x$ pessoas e depois tens coordenações. Metade do grupo parlamentar segue a marcha, segue a música. ${ }^{17}$

Quanto maiores são os grupos e quanto mais densas e complexas as hierarquias, mais se fazem notar lógicas de afirmação e reprodução do grupo dirigente e a formação de uma cultura de verticalidade. A centralização da tomada de decisão reflete-se numa limitação da autonomia individual dos deputados que, sempre que querem agir sobre um determinado tema, têm de ter o aval da liderança do grupo. Como me disse uma veterana: "Há demasiada hierarquia dentro deste Parlamento, isso foi uma das coisas que eu notei com a passagem do tempo. Muitas hierarquias, muitos pedidos de licença. Muita gente com muito medo de fazer coisas sem pedir licença não sei a quem."18

Muitos deputados, do topo e da base, apresentam a hierarquização como uma dimensão inevitável para a estabilidade e reprodução do sistema. Usando as palavras de um deles: "Num país como o nosso, de um certo tipo de cultura cívica muito partidária, quase tribal, se entrarmos num jogo de uma representação individual a governação é impossível"19. Para este deputado, não há forma de garantir, em simultâneo, a estabilidade na governação e o exercício individual da função de deputado. A intermediação dos partidos funciona como uma espada de dois gumes: por um lado, dá estabilidade, previsibilidade e segurança ao sistema; por outro, limita a autonomia individual dos deputados, cuja ação depende da autorização da estrutura hierárquica.

Para além desta hierarquia formal, há outras que com elas que se cruzam. Algumas dependem do momento político já que para deputados de um grupo que suporta o Governo, a sua ação é condiciona, em simultâneo, pela liderança do grupo, do partido e do Governo. Outras decorrem da antiguidade de algumas pessoas na instituição, que têm formas de funcionamento, organização, de intervenção ou visibilidade pública que lhes permitem ter uma posição de poder e autoridade interna distinta da maioria. Finalmente, o percurso biográfico de determinadas pessoas confere igualmente estatuto simbólico de distinção, que pode decorrer, por exemplo, do seu percurso profissional, da sua forte inserção numa determinada área ou da sua visibilidade mediática.

\section{Classes, trajetórias e lugares de poder no campo político}

O que caracteriza sociologicamente o mundo parlamentar? Ao longo destas páginas tentou-se desvendar alguns dos aspetos que melhor caracterizam, objetivamente e subjetivamente, os representantes políticos no campo parlamentar, escrutinando 
parte das suas narrativas biográficas e procurando o que elas revelam sobre o campo político.

Ao entrar neste mundo institucional, esta pesquisa confrontou-se com os discursos genéricos e abstratos, revelando-se uma ambiguidade fundamental: por um lado, os deputados portugueses não se constituem como um grupo social homogéneo, de origens sociais próximas e dotado de idênticas formas de pensar e de agir no mundo parlamentar; mas por outro lado, a sua diversidade interna revela também alguns dos aspetos que fazem deste um campo social e culturalmente bastante circunscrito. Há, portanto, diversidade interna, mas igualmente características dominantes.

Diversidade objetiva já que na Assembleia encontramos pessoas cujo trajeto biográfico se encontra moldado pelas suas trajetórias partidárias, mas outras que tinham um percurso profissional autónomo da vida política. Parlamentares que chegaram à instituição depois de saírem da universidade, e outros que circulam naqueles corredores há mais de três décadas. Representantes com grandes níveis de escolaridade, de profissões liberais e com situações economicamente favorecidas, e outros de profissões menos qualificadas e de distintas origens geográficas.

Diversidade subjetiva, igualmente, já que se alguns deputados se sentem "enguias em água doce", capazes de apreender e manipular o senso prático do campo parlamentar, outros sentem-se "peixes fora de água", evidenciando percursos parlamentares marcados por uma inadaptação às lógicas hierárquicas, burocráticas e sociotécnicas do seu funcionamento.

Sendo esta diversidade bastante notória, ela não oculta a existência de características sociais e culturais dominantes, que condicionam o acesso, a adaptação e permanência ao campo. Tendencialmente o Parlamento é composto por homens, brancos, bastante qualificados, com perfis profissionais elevados, de profissões liberais, oriundos do litoral, e com percursos de polienvolvimento político e institucional. Ou seja, a diversidade interna não invisibiliza a sub-representação de pessoas oriundas ou pertencentes a classes baixas, desfavorecidas, de profissões menos qualificadas ou não-brancas na representação política. O que explica analiticamente esta sub-representação de classe?

Procurar respostas possíveis, implica, do meu ponto de vista, analisar a luta política tendo como fundamento as determinantes sociais que explicam a divisão do trabalho político nas sociedades contemporâneas, isto é, que reduzem a política a uma prática sectorial e (hiper)especializada, com uma participação regulada, que ultrapolitizou o Estado no mesmo processo que despolitizou a sociedade no seu conjunto. Especialização, esta, que circunscreveu a própria noção da política ao 
campo das suas instituições e dos seus profissionais. Só desta forma é possível desnaturalizar os mecanismos sociais (logo, construídos) que produzem e reproduzem a divisão entre "agentes politicamente ativos" e "agentes politicamente passivos", quem está "dentro" e quem está "fora", "atores" e "espectadores" da produção do fenómeno político.

Como se procurou tornar claro, o processo de acesso, adaptação e permanência no campo político, por um conjunto particular de pessoas, é tanto mais favorecido e facilitado, quanto maior é a posse, prévia, de um conjunto articulado de capitais. Capital cultural legítimo, capaz de ser usado como instrumento de agencialidade, isto é, de compreensão e manipulação de um mundo burocratizado e tecnicizado, onde o debate e a produção legislativa são processos relacionais, que implicam a mobilização de conhecimentos técnicos e especializados, logo, uma linguagem codificada e autorreferencial, tendencialmente mais compreendida por quem tem formações académicas e profissionais elevadas.

Capital social, complexo conceito da teoria sociológica (Bourdieu, 1980, 1986; Coleman, 1990; Putnam, 2002), que aqui podemos pensar como um conjunto de recursos sociais, que se adquirem a partir de uma rede duradoura de relações de conhecimento mútuo e de interreconhecimento, isto é, recursos ligados à pertença a um grupo que não só apresenta propriedades comuns (reconhecíveis por quem lhe é externo), como se mantém unido "ligações permanentes e úteis" (Bourdieu, 1980). Capital, este, que fica bem expresso pelas fortes conexões das pessoas à organização partidária que, nas suas diversas escalas e formas, lhes pode providenciar recursos mobilizáveis para trilhar um trajeto de vida que lhe permite aceder material e simbolicamente ao campo político-parlamentar.

Capital simbólico, finalmente, já que o acesso, a permanência e a adaptação implica um crédito firmado na crença, no reconhecimento, autoridade e notoriedade. Capital raro e desigualmente distribuído, ele é recurso crucial para a agencialidade política e depende da socialização prévia dos atores.

A conjugação destes três tipos de capitais - o cultural, decorrente da tecnicidade; o social, decorrente das ligações organizacionais; e o simbólico, decorrente do prestígio - confere aos agentes a possibilidade e a capacidade de produzirem, construírem e manipularem um conjunto de instrumentos de produção do fenómeno político: um corpus de saberes e uma linguagem precisa e distintiva que estrutura as relações de interreconhecimento entre os pares. Relações, essas, que estabelecem simetricamente uma fronteira com quem lhe é exterior, remetida ao estatuto de espectadora ou de consumidora de produtos políticos, tal como eles se jogam institucionalmente.

No quadro de sociedades capitalistas modernas, a relação de alienação que desvincula quem produz, do resultado e produto da produção (Marx, 2007), é 
exatamente a mesma relação que aliena a maioria dos representados do produto da representação política e do voto. Como dirá Bourdieu:

O que faz com que a vida política possa ser descrita na lógica da oferta e da procura é a desigual distribuição dos instrumentos de produção de uma representação do mundo social explicitamente formulada: o campo político é o lugar em que se geram, na concorrência entre o agentes que nele se acham envolvidos, produtos políticos, problemas, programas, análises, comentários, conceitos, acontecimentos, entre os quais o cidadãos comuns, reduzidos ao estatuto de "consumidores" devem escolher, com probabilidades de mal-entendido tanto maiores quanto mais afastados estão do lugar de produção (Bourdieu, 2011, p. 168)

Desta forma, o processo que garante ao campo a sua reprodução, é o mesmo que circunscreve quem dele não faz parte ou a um estatuto de espectador, situado atrás da quarta parede; ou de consumidor, a quem é dada a liberdade de escolher, ritualisticamente, entre os diferentes produtos políticos oferecidos. Assumida a delegação incondicional, aliena-se toda a possibilidade soberana.

Nada é menos natural que o modo de pensamento e de ação que é exigido pela participação no campo político: o habitus político supõe uma preparação especial, como se viu. Implica a aprendizagem continuada de um corpus de saberes específicos (teorias, problemáticas, conceitos, história, dados, tradições...) produzidos e acumulados pelo trabalho político dos profissionais do presente e do passado, e pelo domínio de uma linguagem e uma certa retórica política - de tribuna, essencial para comunicar com o exterior; de hemiciclo, crucial para o debate entre pares.

Neste sentido, a concentração do capital político nas mãos de determinadas classes é tão mais socialmente aceite, quanto mais a maioria dos cidadãos está, ou se sente, desapossada dos instrumentos materiais, culturais e simbólicos necessários à participação política, tal como ela é socialmente percecionada e institucionalmente organizada. Só que o capital político aqui, contrariamente ao que defende Bourdieu, não pode ser interpretado como uma forma específica de capital simbólico. Pelo contrário, parece ser antes um capital compósito, simultaneamente cultural, social e simbólico, que só é realmente distintivo e exclusivo porque tão raro.

O que argumento, enfim, é que distintas origens e pertenças de classe, que estruturam trajetórias biográficas particulares, potenciam ou inibem a possibilidade acesso, adaptação e permanência às engrenagens do campo político e parlamentar. Engrenagens profundamente marcadas por lógicas hierárquicas, burocráticas e sociotécnicas, que favorecem a permanência de umas pessoas, em detrimento de outras. Permanência, essa, essencial para a reprodução do próprio sistema, logo, desta forma particular de entender o que significa "participar politicamente". 
Em suma, o campo político, recurso conceptual mais amplo que nesta pesquisa é uma decorrência analítica do campo parlamentar português, é um subconjunto relacional do espaço social, estruturado através de posições e disposições, istoé, de um habitus político particular, que potencia o agenciamento de determinadas pessoas, em detrimento de outras. Por isso é também desigual a distribuição do capital político, isto é, uma forma de capital compósito, simultaneamente cultural, social e simbólico, desigualmente distribuído, a partir do qual se estabelecem um conjunto de fronteiras assentes em competências, linguagens, valores, retóricas e saberes adquiridos, entre quem está dentro e quem está fora. Fronteiras que, em última análise, estabelecem a lógica fundamental do campo: representa quem pode, é representado quem deve.

\section{Agradecimentos}

O artigo que agora se apresenta, tal como a investigação em que se baseia, foram financiados por uma Bolsa de Doutoramento pela Fundação para a Ciência e a Tecnologia, com a referência SFRH/BD/120193/2016, tendo igualmente o apoio do projeto "Governação, transformações políticas e negociação de quotidianos: Portugal 2008-2018" (PTDC/SOC-ANT/32676/2017).

Agradeço ao projeto "Hemiciclo" (http://hemiciclo.pt/) e à sua generosa equipa a disponibilização de vários dados que ajudaram a fundamentar os argumentos deste artigo, tal como a sua abertura para um diálogo que muito me tem ajudado nesta investigação.

Igualmente agradeço a Ana Nunes de Almeida as sugestões que muito me ajudaram a melhorar a reflexão metodológica e a análise dos perfis dos deputados que aqui são desenvolvidos.

Finalmente, agradeço a Catarina Frois todo apoio, orientação e confiança na realização da pesquisa etnográfica, assim como a José Neves pelos preciosos comentários críticos ao longo deste trajeto de investigação.

\section{Notas}

Por decisão pessoal, o autor do texto escreve segundo o novo acordo ortográfico.

1 Artigo $147^{\circ}$ da Constituição da República Portuguesa.

2 O conjunto dos poderes dos deputados estão vertidos no $156^{\circ}$ da Constituição da República Portuguesa e no artigo $4^{\circ}$ do Regimento da Assembleia da República.

3 O Projeto da Lei Eleitoral para a Assembleia Constituinte, 1974 pode se encontrado aqui: http://app.parlamento.pt/LivrosOnLine/Vozes_Constituinte/med01160000j.html. 
4 Comunidade de prática designa um conjunto de pessoas que interagem e se interrelaciona a partir da participação num mesmo sistema de atividade, partilhando um entendimento comum quanto ao que estão a fazer, independentemente de condições como a copresença ou a existência de fronteiras sociais visíveis entre uma comunidade de prática e outra (Lave e Wenger, 1991). Já por aprendizagem situada refere-se o processo pelo qual uma pessoa se constitui como membro de uma comunidade de prática - uma inserção gradual e progressiva, condicionada pela atividade em causa, destacando-se o carácter relacional de todo o conhecimento apreendido.

5 Estes dados foram coletados pelo projeto "Hemicilo", a quem agradeço a partilha.

6 Agradeço ao projeto "Hemiciclo" a cedência e partilha dos dados das profissões dos deputados que não as tinham declarado no websiste do Parlamento.

7 Veja-se que, por exemplo, apesar Portugal ter perdido 251371 membros da população residente, a Área Metropolitana de Lisboa aumentou 6629 residentes.

8 Agradeço ao projeto "Hemicilo" a disponibilização dos dados relativos ao polienvolvimento políticos dos deputados.

9 Entrevista realizada por João Mineiro, a 16 de maio de 2016.

10 Conversas etnográficas decorrentes de job shadowing realizado a 13 de julho de 2016.

11 Entrevista realizada por João Mineiro a 25 de maio de 2016.

12 Entrevista realizada por João Mineiro a 12 de maio de 2016.

13 Entrevista realizada por João Mineiro, a 19 de maio de 2016.

14 Entrevista realizada por João Mineiro a 10 de novembro de 2015.

15 Entrevista realizada por João Mineiro a 10 de maio de 2016.

16 Entrevista realizada por João Mineiro a 23 de novembro

17 Entrevista realizada por João Mineiro a 10 de novembro de 2015.

18 Entrevista realizada por João Mineiro a 14 de abril de 2016.

19 Entrevista realizada por João Mineiro a 2 de junho de 2016.

\section{Referências}

Abélès, M. (2000). Un ethnologue à l’Assemblée. Paris, França: Odile Jacob.

Becker, H. S. (1998). Tricks of the trade: How to think about your research while doing it.

Chicago, EUA: University of Chicago Press.

Bourdieu, P. (1979). La distinction: Critique sociale du jugement. Paris, França: Editions de Minuit.

Bourdieu, P. (1980). Le capital sociale. Notes provisoires. Actes de la Recherche en Sciences Sociales, 31, 2-3.

Bourdieu, P. (1986). The forms of capital. Em J. G. Richardson (Ed.), Handbook of theory for research in the sociology of education (pp. 241-258). Westport/CT: Greenwood Press.

Bourdieu, P. (2011). A representação política. Elementos para uma teoria do campo político. Em Pierre Bourdieu, O poder simbólico (pp. 167-215). Lisboa: Edições 70.

Coleman, J. S. (1990). Foundations of social theory. Cambridge, EUA: The Belknap Press of Harvard University Press. 
Crewe, E. (2015). The house of commons: An anthropology of MP's at work. Londres, Reino Unido: Bloomsbury.

Ferrari, V. (Ed.) (1990). Developing sociology of law. A world-wide documentary enquiry. Milão, Itália: Giuffré.

Ferreira, A. C., e Pedroso, J. (1999). Entre o passado e o futuro: Contributos para o debate sobre a sociologia do direito em Portugal. Revista Crítica de Ciências Sociais, (52/53), 333-361.

Frois, C. (2017). Mulheres condenadas. Histórias de dentro da prisão. Lisboa, Portugal: Edições Tinta-da-China.

Goffman, E. (1993 [1959]). A apresentação do eu na vida de todos os dias. Lisboa, Portugal: Relógio d'Água.

Joseph, L., Mahler, M., e Auyero, J. (Eds.) (2007). New perspectives in political ethnography. Nova Iorque, EUA: Springer.

Kuppe, R., e Potz, R. (2005). Law and anthropology. Boston, EUA: Martinus Nijhoff Publishers.

Latour, B. (2002). La fabrique du droit. Une ethnographie du Conseil d'État. Paris, França: Éditions La Découverte.

Lave, J., e Wenger, E. (1991). Situated learning: Legitimate peripheral participation. Cambridge, Reino Unido: Cambridge University Press.

Leitão, M., e Santos e Silva, N. (2008). O sistema eleitoral da Assembleia da República. Em A. Vargas, e P. Valete (Eds.), O Parlamento na prática (pp. 6-54). Lisboa, Portugal: Assembleia da República.

Lopes, D. S., Frois, C., Mineiro, J., Carvalheira, Gomes Moreira, R., e Bento, B. (2017). O Estado por dentro: Uma etnografia do poder e da administração pública em Portugal. Lisboa, Portugal: Fundação Francisco Manuel dos Santos.

Luhmann, N. (2004). Law as a social system. Oxford, Reino Unido: Oxford University Press.

Marx, K. (2007 [1844]). Economic and philosophic manuscripts of 1844. Mineola, EUA: Dover Publications.

Mason, J. (2012). Qualitative researching. Thousand Oaks, EUA: Sage.

Putnam, R. D. (Ed.) (2002). Democracies in flux. The evolution of social capital in contemporary society. Oxford, Reino Unido: Oxford University Press.

Tilly, C. (2007). Afterword: Political ethnography as art and science. Em L. Joseph, M. Mahler, e J. Auyero (Eds.), New perspectives in political ethnography (pp. 247-250). Nova Iorque, EUA: Springer.

Weber, M. (2000 [1919]). A política como profissão. Lisboa, Portugal: Edições Universitárias Lusófonas.

Woods, P. (1996). Researching the art of teaching: Ethnography for educational use. Nova Iorque, EUA: Routledge.

Data de submissão: 29/11/2018 | Data de aceitação: 12/02/2019 